\title{
An analytic solution for groundwater uptake by phreatophytes spanning spatial scales from plant to field to regional
}

\author{
David R. Steward • Trevor S. Ahring
}

Received: 1 October 2007 / Accepted: 23 October 2008 / Published online: 18 November 2008

(C) The Author(s) 2008. This article is published with open access at Springerlink.com

\begin{abstract}
Phreatophytes are important to the overall hydrologic water budget, providing pathways from the uptake of groundwater with its nutrients and chemicals to subsequent discharge to the root zone through hydraulic lift and to the atmosphere through evapotranspiration. An analytic mathematical model is developed to model groundwater uptake by individual plants and fields of plant communities and the regional hydrology of communities of fields. This model incorporates new plant functions developed through aid of Wirtinger calculus. Existing methodology for area-sinks is extended to fields of phreatophytes, and Bell polynomials are employed to extend existing numerical methods to calculate regional coefficients for area-sinks. This model is used to develop capture zones for individual phreatophytes and it is shown that the functional form of groundwater uptake impacts capture zone topology, with groundwater being extracted from greater depths when root water uptake is focused about a taproot. While individual plants siphon groundwater from near the phreatic surface, it is shown that communities of phreatophytes may tap groundwater from greater depths and lateral extent as capture zones pass beneath those of upgradient phreatophytes. Thus, biogeochemical pathways moving chemical inputs from aquifer to ecosystems are influenced by both the distribution of groundwater root uptake and the proximity of neighboring phreatophytes. This provides a computational platform to guide hypothesis testing and field instrumentation and interpretation of their data and to understand the function of phreatophytes in water and nutrient uptake across plant to regional scales.
\end{abstract}

Keywords Analytic continuation · Analytic-element method · Bell polynomial · Capture zone · Cauchy integral · Phytoremediation

\section{Introduction}

"Water, the bloodstream of the biosphere, determines the sustainability of living systems" [1]. Groundwater extraction using modern mechanized hydraulics over the past 50 years and their implementation in developing nations over the past 20 years [2], provides society with a water supply that is reliable through drought but often unsustainable

D. R. Steward $(\otimes)$. T. S. Ahring

Department of Civil Engineering, Kansas State University, 2118 Fiedler Hall, Manhattan, KS 66506-5000, USA

e-mail: steward@ksu.edu

T. S. Ahring

e-mail: tsa4555@ksu.edu 
through natural recharge [3]. This motivates studies of groundwater/surface water interactions to forecast future outcomes and inform public authority and groundwater policy innovations [4].

Phreatophytes, plants that directly tap into groundwater resources, are important to the overall water budget in the hydrologic cycle. Their presence is readily observed in diurnal water table fluctuations [5], whereby hydraulic lift from groundwater influences not only the distribution and abundance of the species which use it but also the entire hydrologic balance of the community [6]. Evapotranspiration from phreatophytes has been estimated to represent most of the $20-50 \%$ of total long-term water budget depletions in large river systems that are ascribed to natural vegetation [7], and survival of some species in arid systems has been shown to depend completely on a plant's ability to tap water from permanent water tables [8].

Phreatophytes provide a myriad of ecosystems goods and services. At a global scale, phreatophytes redistribute soil water by drawing water upward and depositing it in drier surface layers, which significantly increases photosynthesis and evapotranspiration, and establishes a direct link between plant-root functioning and global climate [9]. Within riparian corridors, phreatophytes impact flood intensity and channelization of stream networks, and provide wildlife habitat and migratory routes for birds $[10,11]$. While phreatophytes do not directly tap surface water [12], they may intercept groundwater and change the dynamics of groundwater-surface water interactions with consequences to biomass production and species diversity [13]. Phreatophytes impact biogeochemical cycles and initiate a pathway of chemical inputs from aquifers to ecosystems that typically do not exist in groundwater recharge zones [14].

There is a clear need for investigative tools to understand and forecast ecosystem changes induced by human activity, climate change, and changes in species composition. This premise is supported by many recent vision papers on this topic, for example [15-19]. This investigation contributes to this endeavor by developing a new analytic model of groundwater flow in the presence of phreatophytes that is applicable at plant, field and regional scales. This model is used to examine the cumulative impact of diurnal water uptake by phreatophytes and identify source areas for individual plants and plant communities.

\section{Ecohydrology conceptual model}

In [8] a comprehensive study of plant rooting depths across species and environments was conducted. While it is known that water uptake is focused within the root zone in the soil column [6], the mathematical form of the spatial distribution of deep-root distributions near groundwater and groundwater uptake is not known [20]. In fact, the distribution of roots that tap groundwater vary significantly in authors' pictorial depictions from concentrated within the tree canopy [20] to the size of the canopy or larger [6,13,14,21].

A set of mathematically plausible and tractable forms for groundwater uptake by phreatophytes is adopted that satisfy the following assumptions:

1. Groundwater uptake varies radially (in the $r$-direction) with the largest uptake occurring at $r=0$.

2. Groundwater uptake is focused within the area of the canopy.

3. The net discharge of uptake by a phreatophyte is steady and of magnitude $\underset{p}{Q}$.

This steady model and its variables illustrated in Fig. 1a and Table 1 will be used to investigate long-term waterbalance and sources/destinations of water.

Three different functions that satisfy these assumptions will be used to develop understanding of the impact of the functional form on water uptake. The first function is given by a uniform root uptake of $R_{u}$ (negative recharge) over a radius $\underset{p}{r}$ :

$R=\left\{\begin{array}{cc}-R_{p} u & (r \leq \underset{p}{r}) \\ 0 & (r>\underset{p}{r})\end{array}\right.$. 


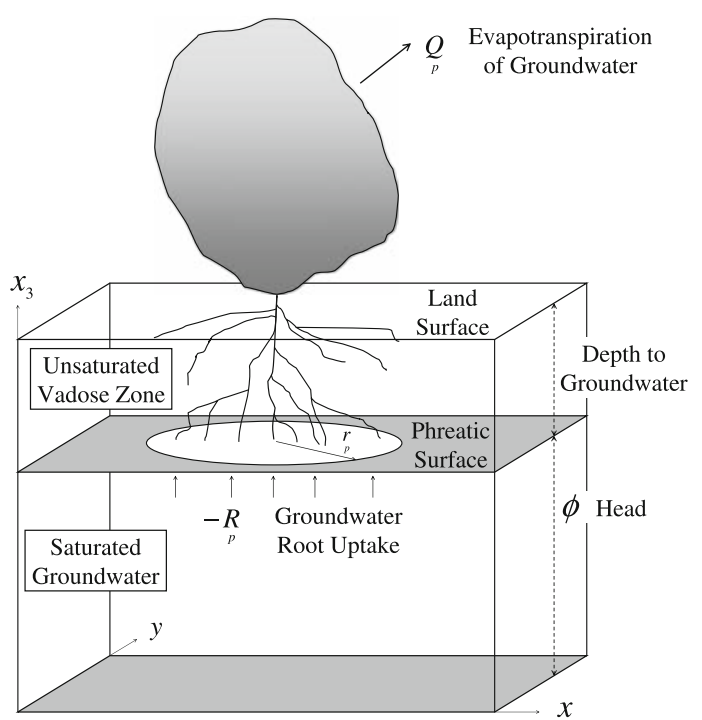

a Groundwater and a phreatophyte

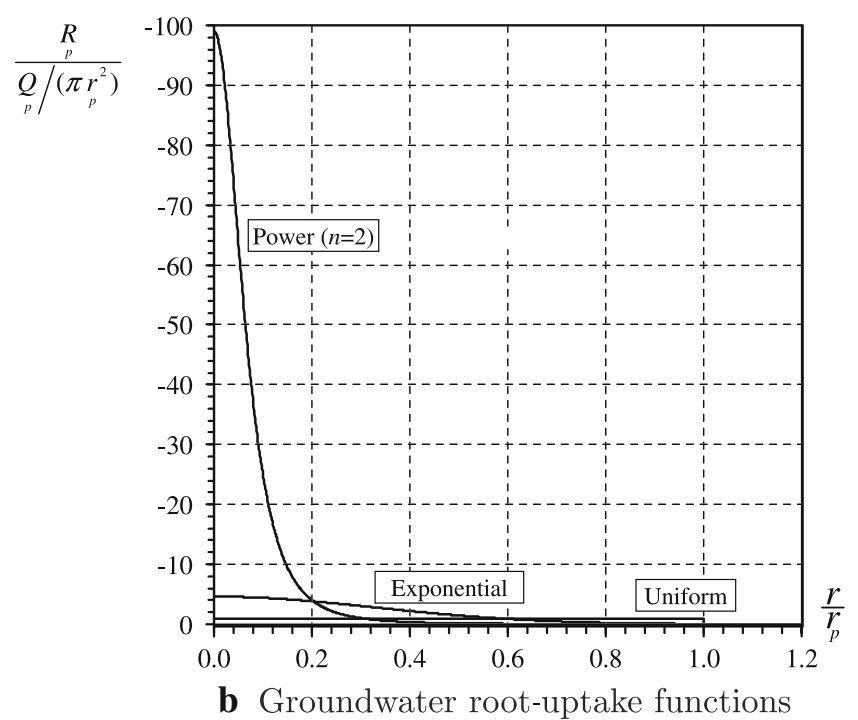

Fig. 1 Variables used to delineate groundwater flow associated with a phreatophyte, and three functional approximations for the specific discharge of groundwater uptake by a phreatophyte presented in dimensionless form

The second function is given by the exponential expression associated with the normal probability density function, $R=-R_{p} \mathrm{e}^{-a r^{2}}$

where $\underset{p}{R_{e}}$ and $\underset{p}{a}$ are coefficients. The third function provides flexibility in distributing the discharge $\underset{p}{Q}$ through variation of the power $n$,

$R=-R_{p} \frac{1}{\left({ }_{p} r^{2}+1\right)^{n}}$,

where $R_{n}$ and $b_{n}$ are coefficients. It may be shown that in the limit as $n \rightarrow \infty$ this power series form reproduces the exponential form with $\underset{p}{R_{e}}={\underset{p}{n}}_{n}$ and $b_{n}=\underset{p}{a} / n$, using $\mathrm{e}^{r}=\lim _{n \rightarrow \infty}\left(\frac{r}{n}+1\right)^{n}$ [22].

The coefficients in these equations are determined by explicitly setting the net discharge of plant uptake from groundwater equal to $\underset{p}{Q}$ :

$Q=-\int_{0}^{\infty} 2 \pi r R \mathrm{~d} r$.

A second condition is required to determine $\underset{p}{a}$ and $b_{n}$ for the exponential and power forms. Here, the condition that a vast majority (99\%) of root uptake occurs within a radius $\underset{p}{r}$ gives

$0.99 \underset{p}{Q}=-\int_{0}^{r} 2 \pi r R \mathrm{~d} r$.

These conditions lead to expressions for the coefficients in terms of $\underset{p}{Q}$ and $\underset{p}{r}$ :

$\underset{p}{R_{u}}=\frac{\underset{p}{Q}}{\pi r_{p}^{2}}$, 
Table 1 Notation

\begin{tabular}{|c|c|c|}
\hline Symbol & Dimensions & Variable \\
\hline $\mathbf{B}_{k j}$ & & Bell polynomial coefficients \\
\hline $\mathbf{C}_{n j}$ & - & Far-field correction coefficients \\
\hline $\mathbf{F}_{n j}$ & - & Far-field expansion coefficients \\
\hline$Q$ & $\mathrm{~L}^{3} / \mathrm{T}$ & Discharge \\
\hline$r$ & $\mathrm{~L}$ & Distance in radial direction \\
\hline$R$ & $\mathrm{~L} / \mathrm{T}$ & Recharge \\
\hline$-R_{e}$ & $\mathrm{~L} / \mathrm{T}$ & Groundwater uptake for exponential distribution \\
\hline$-R_{n}$ & $\mathrm{~L} / \mathrm{T}$ & Groundwater uptake for power distribution \\
\hline$-R_{u}$ & $\mathrm{~L} / \mathrm{T}$ & Groundwater uptake for uniform distribution \\
\hline$s$ & $\mathrm{~L}$ & Distance in streamwise direction of flow \\
\hline$T_{m}$ & & Chebyshev polynomial of the first kind \\
\hline $\mathbf{T}_{m n}$ & & Chebyshev coefficients \\
\hline$w=v_{x}+\mathrm{i} v_{y}$ & $\mathrm{~L}^{2} / \mathrm{T}$ & Discharge per width in physical coordinates \\
\hline$W=V_{X}+\mathrm{i} V_{Y}$ & - & Discharge per width in local coordinates \\
\hline$x, y$ & $\mathrm{~L}$ & Horizontal coordinate axes \\
\hline$x_{3}$ & $\mathrm{~L}$ & Vertical coordinate axis \\
\hline$z=x+\mathrm{i} y$ & $\mathrm{~L}$ & Location in physical coordinates \\
\hline$Z=X+\mathrm{i} Y$ & - & Location in local coordinates \\
\hline$\alpha$ & - & Orientation of a line element \\
\hline$\lambda$ & $\mathrm{L}$ & $\frac{1}{2}$ length of a line element \\
\hline$\mu$ & $\mathrm{L}^{3} / \mathrm{T}$ & Line-doublet strength \\
\hline$v$ & $\mathrm{~L}^{3} / \mathrm{T}$ & Line-dipole strength \\
\hline$\phi$ & $\mathrm{L}$ & Head (groundwater elevation) \\
\hline$\Phi$ & $\mathrm{L}^{3} / \mathrm{T}$ & Potential function \\
\hline$\Psi$ & $\mathrm{L}^{3} / \mathrm{T}$ & Stream function \\
\hline$\Omega=\Phi+\mathrm{i} \Psi$ & $\mathrm{L}^{3} / \mathrm{T}$ & Complex potential \\
\hline$(\cdot)$ & & Variable $(\cdot)$ for field number $f$ \\
\hline$(\cdot)$ & & Variable $(\cdot)$ for line number $l$ \\
\hline$(\cdot)$ & & Variable $(\cdot)$ for phreatophyte number $p$ \\
\hline
\end{tabular}

$$
\begin{aligned}
\underset{p}{R_{e}}= & \frac{\underset{p}{Q} \log (100)}{\pi r_{p}^{2}}, \quad \underset{p}{a}=\frac{\log (100)}{r_{p}^{2}}, \\
{\underset{p}{n}}_{n} & =\frac{\underset{p}{Q}(n-1)\left(100^{\frac{1}{n-1}}-1\right)}{\pi r_{p}^{2}}, \quad{ }_{p}=\frac{100^{\frac{1}{n-1}}-1}{r_{p}^{2}} .
\end{aligned}
$$

These functional forms for groundwater uptake are illustrated in Fig. $1 \mathrm{~b}$.

\section{Plant-scale groundwater model}

Groundwater flow is assumed to satisfy Darcy's Law, conservation of mass and the Dupuit Assumption, and may be represented using mathematical functions that satisfy the Laplace equation for steady flow without recharge [23, Eqs. 17.8, 19.16]

$$
\frac{\partial^{2} \Omega}{\partial x^{2}}+\frac{\partial^{2} \Omega}{\partial y^{2}}=0
$$

where $x$ and $y$ are horizontal coordinate axes, the complex potential $\Omega$ is a function of $z=x+\mathrm{i} y$ and $\mathrm{i}=\sqrt{-1}$. This function may be separated into real and imaginary parts 
$\Omega(z)=\Phi(z)+\mathrm{i} \Psi(z)$,

where the groundwater flow is directed towards $-\nabla \Phi$, the direction of maximal rate of decrease in the potential $\Phi$, and tangent to streamlines of constant Lagrange stream function $\Psi$. The potential is related to groundwater head, $\phi,[24]$

$\Phi=\left\{\begin{array}{ll}\frac{1}{2} k(\phi-B)^{2} & (\phi-B)<D \\ k D(\phi-B)-\frac{1}{2} k D^{2} & (\phi-B) \geq D\end{array}\right.$,

where $k$ is the hydraulic conductivity, $B$ is the elevation of the aquifer base, and $D$ is the thickness of the aquifer. The discharge per width, with components $v_{x}$ and $v_{y}$, may be obtained from the complex conjugate of the derivative of $\Omega$ with respect to $z$ [25]

$w(z)=v_{x}(z)+\mathrm{i} v_{y}(z)=-\frac{\overline{\mathrm{d} \Omega}}{\mathrm{d} z}$.

Note that $w$ is defined as the complex conjugate of common notation [e.g. see $w=v_{x}-\mathrm{i} v_{y}$ in [23, Sect. 24]]. This convention is adopted here so the kernel functions of the line elements presented later reproduce those in [25].

Wirtinger calculus $[26,27]$ extends two-dimensional complex functions to divergent vector fields (i.e., recharge or phreatophyte groundwater uptake) by expressing $\Phi(z, \bar{z})$ as functions of both $z$ and its complex conjugate, $\bar{z}$. This real potential function satisfies [28]

$\frac{\partial^{2} \Phi}{\partial x^{2}}+\frac{\partial^{2} \Phi}{\partial y^{2}}=4 \frac{\partial^{2} \Phi}{\partial z \partial \bar{z}}=-2 \frac{\partial w}{\partial z}=-R(z, \bar{z})$,

where $R$ is the divergence of the vector field, and the vector field is given by

$w(z, \bar{z})=v_{x}(z, \bar{z})+\mathrm{i} v_{y}(z, \bar{z})=-2 \frac{\overline{\partial \Phi}}{\partial z}=-2 \frac{\partial \Phi}{\partial \bar{z}}$.

This notation is consistent with the convention for $w$ in (8) for divergent-free, irrotational flow. The vector field and potential may be obtained for a vector field with given divergence (recharge) using integral forms of these equations:

$w(z, \bar{z})=\frac{1}{2} \int R \mathrm{~d} z+f(\bar{z})$

and

$\Phi(z, \bar{z})=-\frac{1}{2} \int \bar{w} \mathrm{~d} z+g(\bar{z})$,

where $f$ and $g$ are functions of $\bar{z}$. Note that $R$ must be real for the flow field to be irrotational and representable by a scalar potential as per Helmholtz Theorem $[R$ in the groundwater root-uptake functions (1) is real]. Due to the linearity of the partial differential equations (5) and (9), the potential functions in (6) and (12) may be superimposed to provide the groundwater elevation using (7) for functions with divergence (e.g. phreatophytes) and those without (e.g. regional uniform flow).

The discharge vector associated with a phreatophyte located at $\underset{p}{z}$ is obtained through the integration process in (11). For a uniform groundwater uptake, this gives

$\stackrel{\mathrm{ph}}{w}=\left\{\begin{array}{ll}\frac{1}{2} \int-R_{p} \mathrm{~d} z+f_{1}(\bar{z}) & (r \leq \underset{p}{r}) \\ \frac{1}{2} \int 0 \mathrm{~d} z+f_{2}(\bar{z}) & (r>\underset{p}{r})\end{array}\right.$. 
Integrating and choosing $f_{1}$ such that $w=0$ at $z=\underset{p}{z}$ and $f_{2}$ such that $w$ is continuous across $|z-\underset{p}{z}|=\underset{p}{r}$ gives

$\mathrm{ph}=\left\{\begin{array}{cc}-\frac{R_{u}}{2}(z-\underset{p}{z}) & (r \leq \underset{p}{r}) \\ -\frac{R_{u} r_{p}^{2}}{2} \frac{1}{\overline{z-z_{p}}} & (r>\underset{p}{r})\end{array}\right.$

with $f_{1}(\bar{z})=R_{p} z_{p} / 2$, and $f_{2}(\bar{z})=-R_{p} r_{p}^{2} /[2(\overline{z-z})]$. Integrating for the exponential distribution of groundwater uptake and setting $w=0$ at the center of the phreatophyte gives

$\stackrel{\mathrm{ph}}{w}=\frac{R_{e}}{2 a} \frac{1}{\overline{z-z}}\left(\mathrm{e}^{-a r^{2}}-1\right)$

with $f(\bar{z})=-\underset{p}{R_{e}} /[\underset{p}{a}(\overline{z-z})]$. Likewise, the power distribution gives

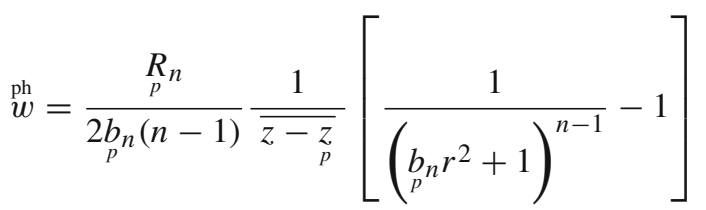

with $f(\bar{z})=-\underset{p}{R_{n}} /\left[2 b_{p}(n-1)(\overline{z-z})\right]$ using the integral (12.10b) in [29].

The potential for a phreatophyte is obtained by integrating the discharge vector, which gives for a uniform groundwater uptake:

$\Phi=\left\{\begin{array}{ll}-\frac{1}{2} \int-\frac{{ }_{p} u}{2} \overline{z-z_{p}} \mathrm{~d} z+g_{1}(\bar{z}) & (r \leq \underset{p}{\mathrm{ph}}) \\ -\frac{1}{2} \int-\frac{{ }_{p} r_{p}^{2}}{2} \frac{1}{z-\underset{p}{2}} \mathrm{~d} z+g_{2}(\bar{z}) & (r>\underset{p}{r})\end{array}\right.$.

Integrating and choosing $g_{1}$ and $g_{2}$ such that $\Phi=0$ at $|z-\underset{p}{z}|=\underset{p}{r}$ gives

$\stackrel{\mathrm{ph}}{\Phi}= \begin{cases}\frac{{ }_{p} u}{4}\left(r^{2}-r_{p}^{2}\right) & (r \leq \underset{p}{r}) \\ \frac{R_{u} r_{p}^{2}}{2} \log \frac{r}{r} & (r>\underset{p}{r})\end{cases}$

with $g_{1}(\bar{z})=-\left(\underset{p}{R_{u}} / 4\right)\left[\underset{p}{z}\left(\overline{z-z_{p}}\right)+\underset{p}{r}\right]$, and $g_{2}(\bar{z})=\left(\underset{p}{R_{u}} r_{p}^{2} / 4\right) \log \left[\left(\overline{z-z_{p}}\right) / r_{p}^{2}\right]$. The exponential distribution of groundwater uptake gives

$\left.\stackrel{\mathrm{ph}}{\Phi}=\frac{\underset{p}{R_{e}}}{4 \underset{p}{a}}\left[E_{1}\left(\underset{p}{a r^{2}}\right)-E_{1} \underset{p p}{a r^{2}}\right)+2 \log \underset{p}{r}\right]$,

on using the Exponential integral, [22,29]

$E_{1}(x)=\int_{x}^{\infty} \frac{\mathrm{e}^{-t}}{t} \mathrm{~d} t$

with $g(\bar{z})=\left[\underset{p}{R_{e}} /(\underset{p}{a})\right]\left[-E_{1} \underset{p}{a} r^{2}\right)+\log \left[(\overline{z-z}) / r_{p}^{2}\right]$. Likewise, the power series distribution gives 
$\stackrel{\mathrm{ph}}{\Phi}=\frac{{ }_{p}}{4 b_{n}(n-1)}\left\{\log \frac{{ }_{p} r^{2}+1}{b_{n} r_{p}^{2}+1}-\sum_{\nu=1}^{n-2} \frac{1}{v}\left[\frac{1}{\left(b_{n} r^{2}+1\right)^{v}}-\frac{1}{\left(b_{p} r_{p}^{2}+1\right)^{v}}\right]\right\}$,

on using an equation adapted from (12.9a)in [29],

$$
\int \frac{\mathrm{d} x}{x(c x+1)^{n-1}}=-\log \frac{c x+1}{x}+\sum_{\nu=1}^{n-2} \frac{1}{v(c x+1)^{\nu}} \quad(n \geq 2)
$$

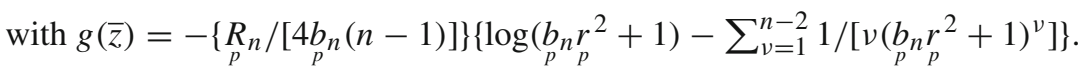

The potential and discharge vector for an isolated phreatophyte is illustrated in Fig. 2. Each plant has the far-field behavior in the limit as $r \rightarrow \infty$ of $\stackrel{\mathrm{ph}}{\Phi}=\underset{p}{Q} /(2 \pi) \log r$, which is a point-sink with discharge $\underset{p}{Q}$ located at the center of the plant. In the near-field, the drawdown beneath the center of the plant is smallest for the uniform distribution and largest for the power distribution where uptake is focused about $r=0$.

\section{Field-scale model}

A field-scale model of phyreatophytic groundwater uptake is obtained by summing the contributions of all plants within a field. The study region, shown in Fig. 3, is located near the Larned test site in [5] with site characteristics
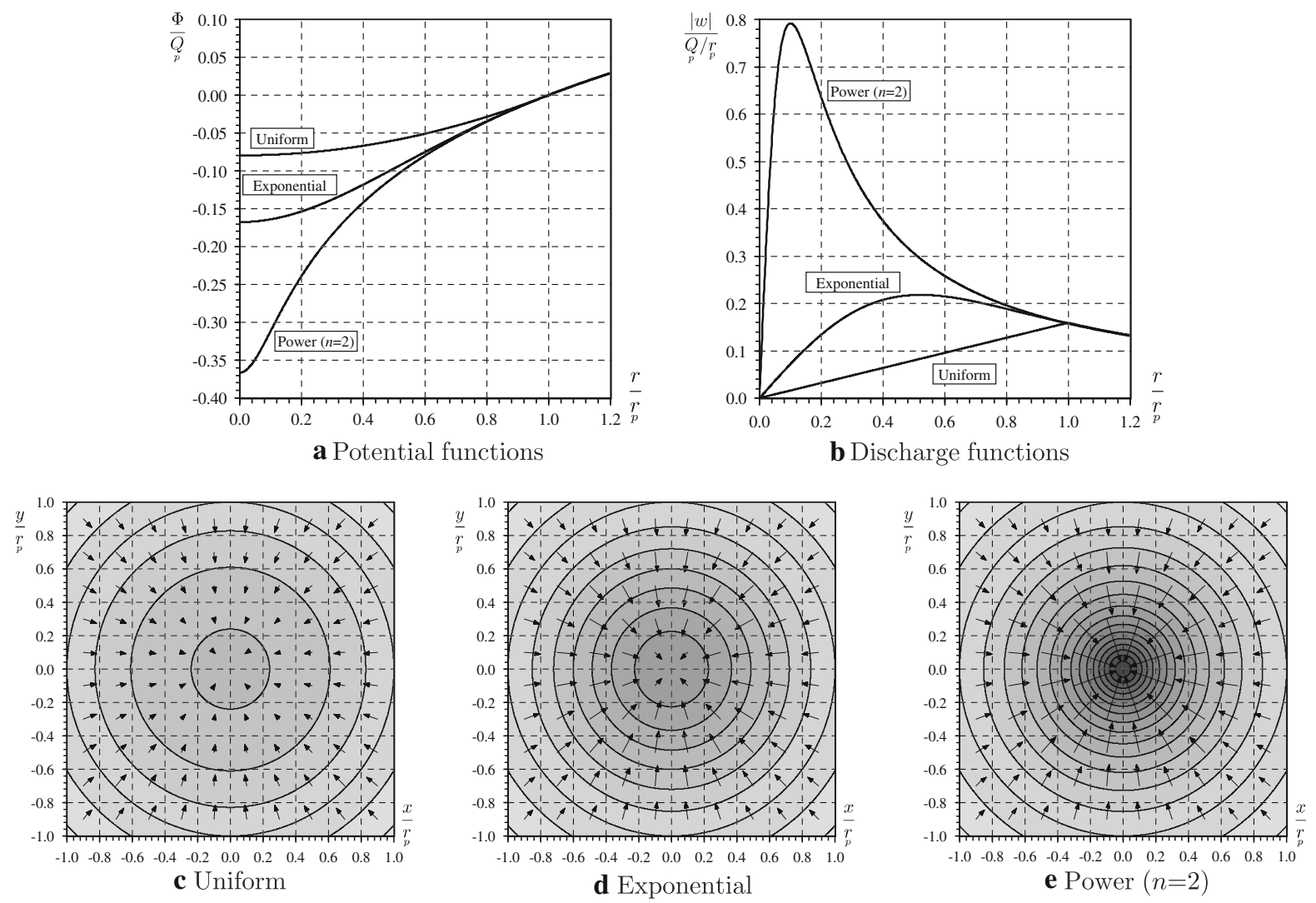

Fig. 2 The functional forms used to approximate the potential and discharge associated with groundwater uptake by a phreatophyte presented in dimensionless form, and contours of groundwater elevation (contoured at consistent intervals) and vectors pointing in the direction of groundwater flow and scaled by its magnitude 
described there. The conceptual model of this region (Fig. 3b) was obtained by digitizing fields and plants, and contains over 1,000 plants with radii $\underset{p}{r}$ that ranges between 2.4 and $12.7 \mathrm{~m}$ with average radius of $5.0 \mathrm{~m}$. Note that additional features may modify groundwater/surface water interactions (e.g. sloping land surface/roadways, ephemeral streams and surface water) that have not been incorporated in this conceptual model. Such features could be incorporated with the phreatophytes presented here using existing analytic elements, for example, using the line and area elements implemented in NAGROM, the NAtional GROundwater Model of The Netherlands [30].

The potential and vector field are obtained by summing the contributions over all phreatophytes within a field, giving

$$
\begin{aligned}
& \Phi_{f}^{i}(z)=\left\{\begin{array}{ll}
\sum_{p} \Phi(z, \bar{z}, \underset{p}{z}, \underset{p}{r}, \underset{p}{Q}) & z \in \underset{f}{\mathcal{D}} \\
0 & z \notin \mathcal{D}_{f}
\end{array},\right. \\
& {\underset{f}{w}}^{i}(z)=\left\{\begin{array}{ll}
\sum_{p} \mathrm{ph}_{w}^{\mathrm{ph}}(z, \bar{z}, \underset{p}{z}, \underset{p}{r}, \underset{p}{Q}) & z \in{\underset{f}{f}}_{f}^{\mathcal{D}} \\
0 & z \notin \mathcal{D}_{f}^{\mathcal{D}}
\end{array},\right.
\end{aligned}
$$

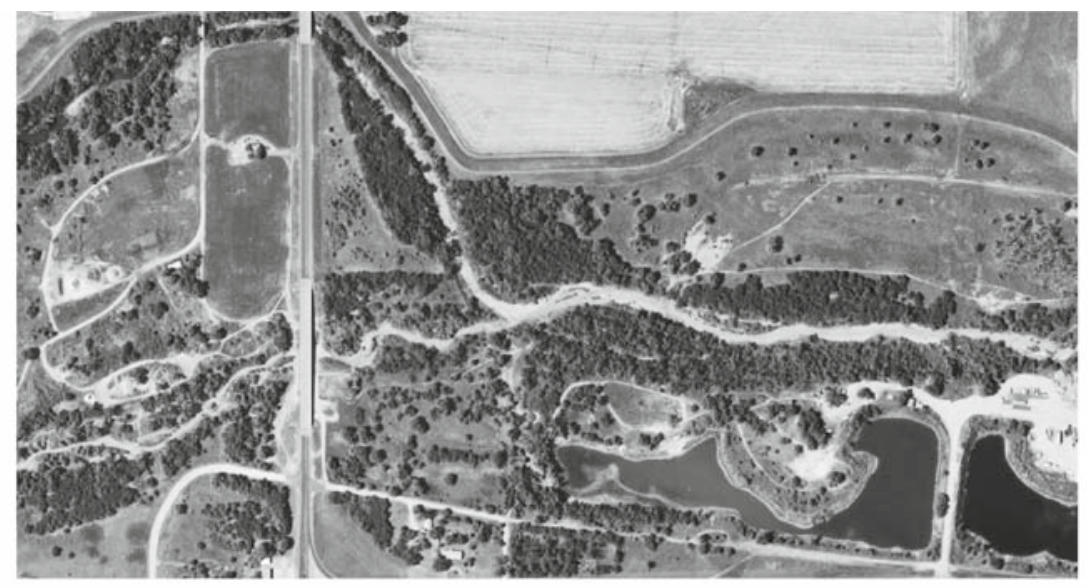

a Aerial photograph

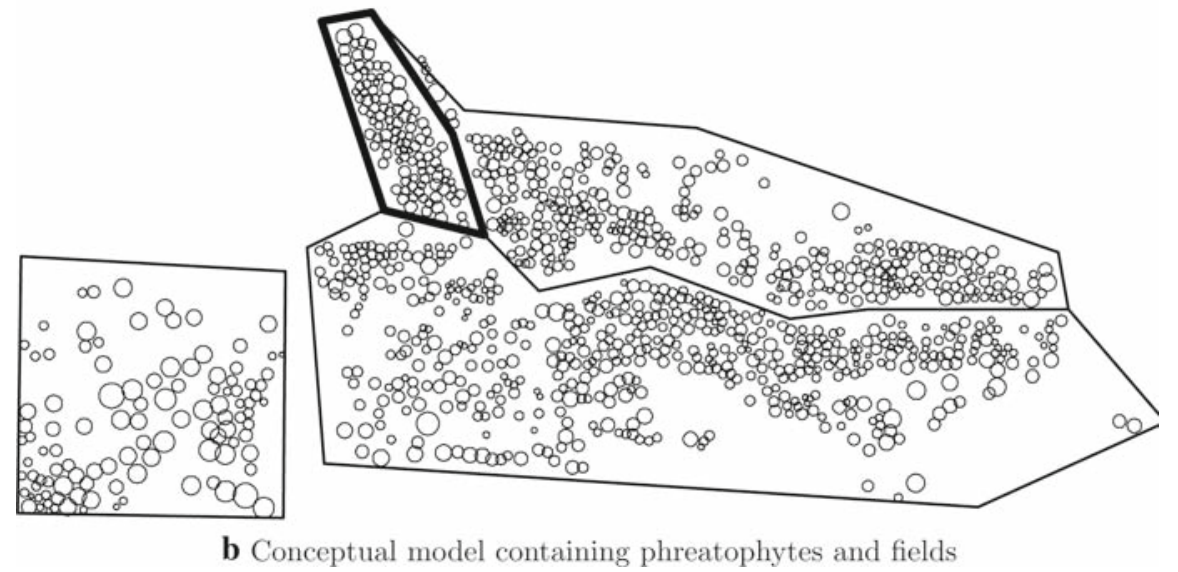

Fig. 3 Phreatophytes (cottonwoods) and fields along approximately $1 \mathrm{~km}$ of the Arkansas River corridor in central Kansas, USA. The northernmost field in the center of the conceptual model (with thicker border) is used to illustrate line elements in subsequent diagrams 

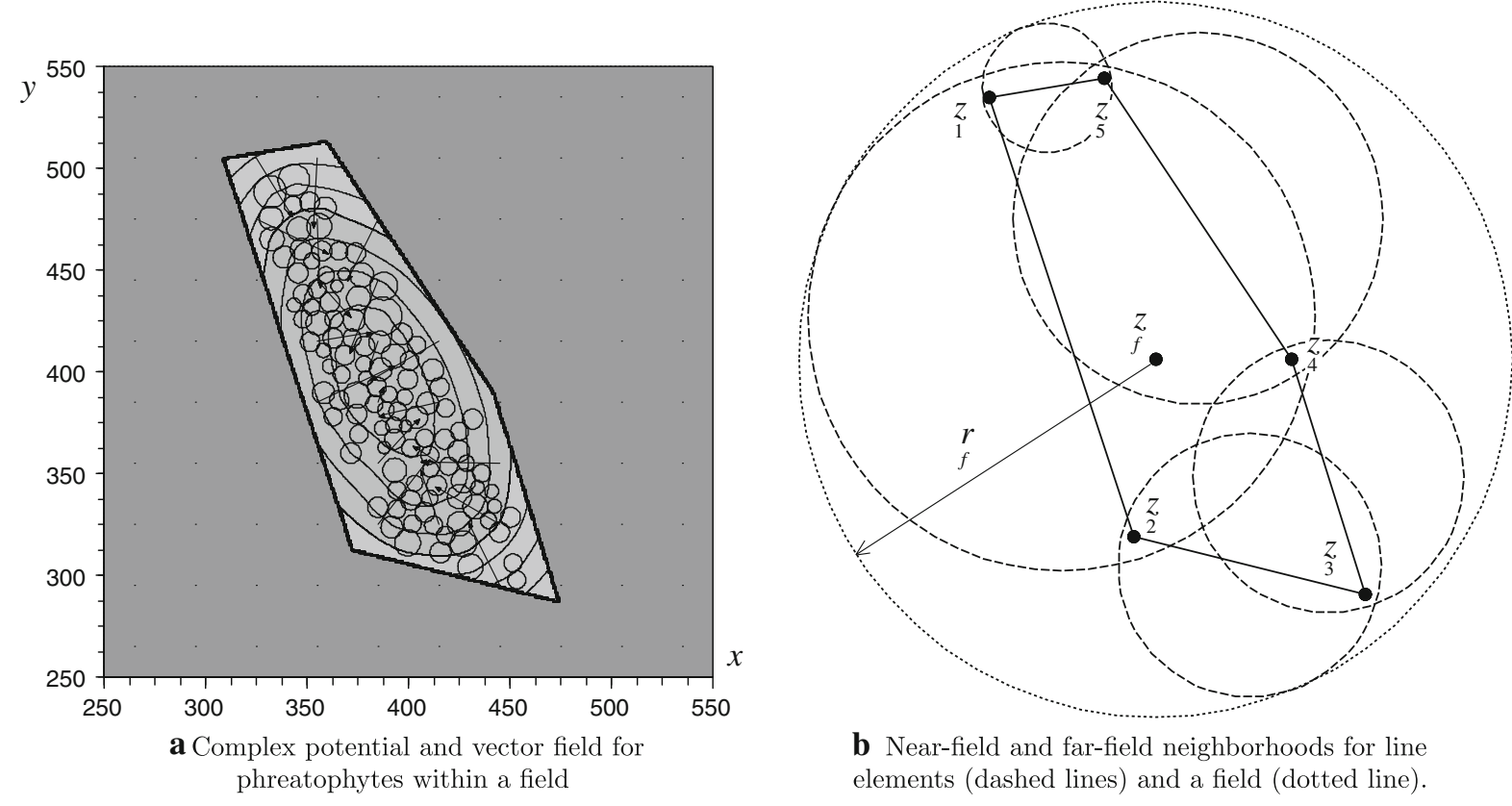

Fig. 4 The groundwater flow associated with phreatophytes that lie in a field, and the neighborhoods used to formulate mathematical expressions associated with a field and the line elements that encircle it

where the function $\stackrel{\mathrm{ph}}{\Phi}$ is given by (16) and $\stackrel{\mathrm{ph}}{w}$ is given by (14). Such superposition is possible due to linearity of the governing partial differential equations. These functions are illustrated in Fig. 4a for the north field in Fig. $3 \mathrm{~b}$.

While these potential and discharge functions may be computed at any point $z$, they are only evaluated at locations within the field in this figure as per [23, Sect. 37]. Outside the field, a simpler mathematical form is obtained by extending the concept of an area-sink to a field of phreatophytes, a methodology that has previously been applied to groundwater uptake with functional forms of polynomials [23, Sect. 37] and multi-quadrics [31]. An area-sink utilizes line elements of Cauchy integrals along the boundary of the field to satisfy the conditions of continuity of head and continuity of flow.

\subsection{Mathematical expressions for line elements}

The line elements that lie at the boundary of the field in Fig. 4a are illustrated in Fig. 4b, where 5 straight lines connect the points $z_{l}$. This figure shows a circle about each line element that delineates a near-field and far-field for the line element, as well as a circle centered at $\underset{f}{z}$ with radius $\underset{f}{r}$ that encompasses the near field of all line elements. As will be shown, the mathematical forms for a field are very numerically efficient outside this circle.

To simplify mathematical expressions, each straight line element (e.g. between end points $\underset{l}{z}$ and $\underset{l+1}{z}$ ) is translated, rotated and scaled to a standardized $Z$-plane, with end points at $Z=-1$ and $Z=1$, using [23, p. 284]

$\underset{l}{Z}(z)=\left(z-\frac{\underset{l+1}{z}+z_{l}}{2}\right) \frac{2}{\underset{l+1}{z-z_{l}} .}$

Cauchy integrals will be placed along each line, which represent a line-doublet (double layer) that generates a jump in potential and a line-dipole that generates a jump in the normal component of flow. The strength of a line-doublet, $\mu$, and line-dipole, $v$, is approximated using Chebyshev polynomials, following [32], 
$\mu(Z)=\sum_{m=0}^{M} \mu_{m} T_{m}(Z), \quad v(Z)=\sum_{m=0}^{M} v_{m} T_{m}(Z)$,

where the $m$ th Chebyshev polynomials of the first kind are given by [22]

$T_{0}(Z)=1$,

$T_{1}(Z)=Z$,

$T_{m}(Z)=2 Z T_{m-1}(Z)-T_{m-2}(Z) \quad(m \geq 2)$.

It is convenient to gather the Chebyshev coefficients in the matrix $\mathbf{T}_{m n}$,

$\mu(Z)=\sum_{m=0}^{M} \mu_{m} \sum_{n=0}^{M} \mathbf{T}_{m n} Z^{n}, \quad v(Z)=\sum_{m=0}^{M} v_{m} \sum_{n=0}^{M} \mathbf{T}_{m n} Z^{n}$,

where

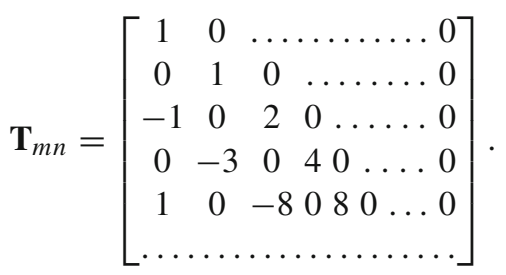

The complex potential for the set of line-doublets and line-dipoles along the boundary of a field is obtained by summing the contributions over all $L$ line elements:

$\Omega(z)=\sum_{l=1}^{L}\left\{\sum_{m=0}^{M} \mu_{l} \sum_{n=0}^{m} \mathbf{T}_{m n}{ }^{\text {ldb }} \Omega_{n}\left[Z_{l}(z)\right]+\sum_{m=0}^{M} v_{l} \sum_{n=0}^{m} \mathbf{T}_{m n}{ }_{l}^{\text {ldp }} \Omega_{n}\left[{ }_{l}(z)\right]\right\}$,

where the kernel functions $\Omega_{n}$ and $\Omega_{n}$ are a generalization of [23, Sect. 38] and are fully derived in [25] and take on the following forms in the near-field and far-field of a line:

$\stackrel{\mathrm{ldb}}{\Omega}_{n}=-\mathrm{i} \Omega_{n}^{\mathrm{ldp}}=\frac{\mathrm{i}}{2 \pi}\left(Z^{n} \log \frac{Z+1}{Z-1}-\sum_{j=1}^{\mathrm{int}} \frac{\frac{n+1}{2}}{2 j-1} Z^{n+1-2 j}\right)=\frac{\mathrm{i}}{2 \pi} \sum_{j=\text { int } \frac{n+3}{2}}^{\infty} \frac{2}{2 j-1} Z^{n+1-2 j} \quad(|Z|>1)$

The vector field for the line-doublets and line-dipoles along a field is given by

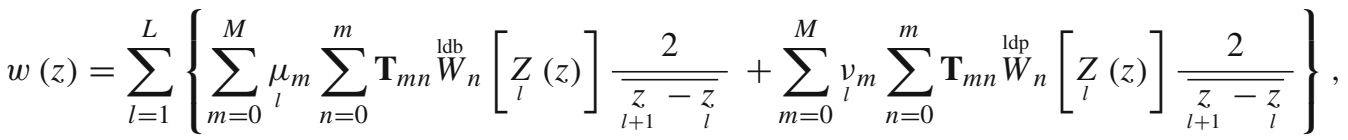

where the derivatives of the kernel functions in the near-field an far-field are [25]:

$$
\begin{aligned}
& \stackrel{\operatorname{ldb}}{W}_{n}=\mathrm{i} W_{n}=\frac{\mathrm{i}}{2 \pi} \overline{\left[n Z^{n-1} \log \frac{Z+1}{Z-1}+\frac{(-1)^{n}}{Z+1}-\frac{1}{Z-1}-n \sum_{j=1}^{\operatorname{int} \frac{n}{2}} \frac{2}{2 j-1} Z^{n-2 j}\right]} \\
& =\frac{\mathrm{i}}{2 \pi} \sum_{j=\text { int } \frac{n+3}{2}}^{\infty} \frac{2(n+1-2 j)}{2 j-1} \overline{Z^{n-2 j}} \quad(|Z|>1) \text {. }
\end{aligned}
$$

4.2 The strength of line elements

The strengths of the line-doublets and line-dipoles are adjusted to satisfy continuity of head and continuity of flow conditions [23, Sect. 37]. The strength of a line-doublet is equal to the jump in potential across the element

$\mu(X)=\Delta \Phi(X)$, 
where $X=\mathfrak{R e} Z$. The coefficients $\mu_{l}$ are obtained by satisfying this condition at a set of $K$ control points uniformly distributed along the $l$ th line-doublet located at

$$
X_{k}=-1+\frac{2 k-1}{K}, \quad z_{l}=X_{k} \frac{\underset{l+1}{z+z_{l}}}{2}+\frac{\underset{l+1}{z}+z_{i}}{2} \quad(k=1, K) .
$$

This leads to a system of $K$ equations for the $M+1$ coefficients

$$
\sum_{m=0}^{M}\left(\sum_{n=0}^{M} X_{k}{ }^{n} \mathbf{T}_{n m}\right) \mu_{l}= \pm \underset{f}{\Phi_{l}^{i}}\left(z_{l}\right) \quad(k=1, K)
$$

where the \pm sign is positive for line-doublets that encircle the field in the clockwise direction. Results are found in Fig. 5a, where $M=10, K=4(M+1)$ and the system of equations is satisfied in a least-squares sense [32].

The strength of a line-dipole is related to the jump in stream function and the normal component of the vector field across the element by

$v(X)=\Delta \Psi(X), \quad \frac{1}{\lambda} \frac{\mathrm{d} v}{\mathrm{~d} X}(X)=\Delta v_{n}(X)$,

where an element is of length $2 \lambda$ and orientation $\alpha$, which may be written for the $l$ th line element as

$\underset{l}{\lambda}=\frac{\left|\begin{array}{c}z \\ l+1\end{array}-z_{i}\right|}{2}, \quad \underset{l}{\alpha}=\arg \left(\underset{l+1}{z}-z_{l}\right)$.

This leads to a system of $K$ equations for $M$ coefficients

$\frac{1}{\lambda} \sum_{l}^{M}\left(\sum_{n=1}^{M} n X_{k}^{n-1} \mathbf{T}_{n m}\right) \nu_{l}= \pm \mathfrak{I m}\left[w_{f}^{i}\left(z_{l}\right) \mathrm{e}^{-\mathrm{i} \alpha} l\right] \quad(k=1, K)$.

Following [31], the coefficients $\nu_{l}$ are chosen such that $\Delta \Psi$ is continuous across adjacent line elements. Setting $\Delta \Psi=0$ at $\underset{L+1}{z}$ leads to

$\nu_{l}= \begin{cases}0-\sum_{m=1}^{M} v_{l} \sum_{n=0}^{m} \mathbf{T}_{m n} & (l=L), \\ \sum_{m=0}^{M} v_{l+1} m \sum_{n=0}^{m} \mathbf{T}_{m n}(-1)^{n}-\sum_{m=1}^{M} v_{l} \sum_{n=0}^{m} \mathbf{T}_{m n} & (l \neq L) .\end{cases}$
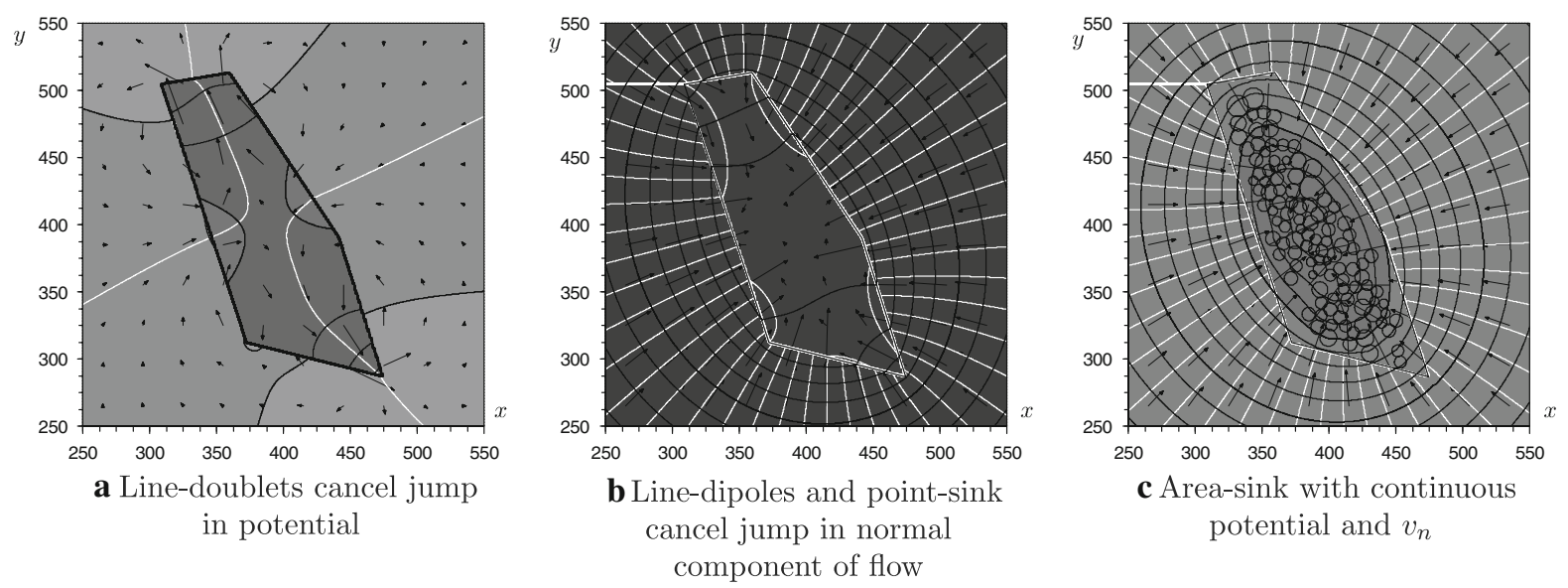

Fig. 5 Complex potential and vector field for an area-sink 
Following [23, Sect. 37], a point-sink of strength $\underset{f}{Q}$ is placed at the first point $\underset{1}{z}$

$\Omega=\frac{Q}{2 \pi} \log \left(z-z_{1}\right)$

where $\underset{f}{Q}$ is equal to the net jump in stream function created by the line-dipoles

$\underset{f}{Q}=\sum_{m=0}^{M} v_{1} \sum_{n=0}^{m} \mathbf{T}_{m n}(-1)^{n}$

Figure $5 \mathrm{~b}$ illustrates the vector field generated by the line-dipoles and point-sink.

\subsection{Numerically efficient computation of $\Omega$ and $w$}

The complex potential for the phreatophytes within a field is obtained by summing the complex potentials for all plants within the field (18) for the line elements along the fields (25) and for a point-sink (36). This is illustrated in Fig. 5c.

The complex potential for $l$ th line element contains nested summations in the near-field of the line

$\Omega_{l}(z)=\frac{1}{2 \pi} \sum_{m=0}^{M}\left(\begin{array}{c}\mathrm{i} \mu_{m}-v_{l} \\ l\end{array}\right) \sum_{n=0}^{m} \mathbf{T}_{m n}\left(\left[Z_{l}(z)\right]^{n} \log \frac{Z_{l}(z)+1}{Z_{l}(z)-1}-\sum_{j=1}^{\operatorname{int} \frac{n+1}{2}} \frac{2}{2 j-1}\left[Z_{l}(z)\right]^{n+1-2 j}\right)$

and in the far-field outside $\underset{l}{r}>1$

$\Omega_{l}(z)=\frac{1}{2 \pi} \sum_{m=0}^{M}\left(\begin{array}{c}\mathrm{i} \mu_{m}-v_{l} \\ l\end{array}\right) \sum_{n=0}^{M} \mathbf{T}_{m n} \sum_{j=\mathrm{int} \frac{n+3}{2}}^{\mathrm{int}} \frac{2}{2 j-1}\left[Z_{l}(z)\right]^{n+1-2 j} \quad(|Z|>\underset{l}{2})$,

where the upper limit of the far-field expansion is chosen such that the truncated series contains numerically significant terms. These equations may be rearranged for elements with known strength coefficients to provide numerically tractable forms.

It is convenient to express the innermost summation in matrix form, which gives the following for the near-field:

$$
\sum_{j=1}^{\operatorname{int} \frac{n+1}{2}} \frac{2}{2 j-1} Z^{n+1-2 j}=\sum_{j=0}^{M-1} \mathbf{C}_{n j}\left[Z_{l}(z)\right]^{-j},
$$

where

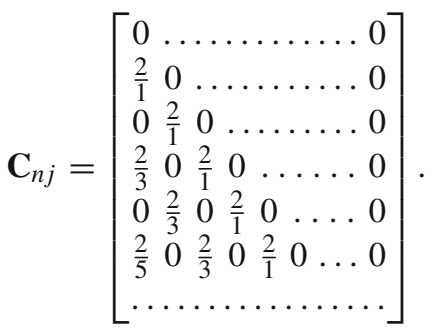

This gives

$$
\begin{aligned}
& \underset{l}{\Omega}(z)=\left\{\sum_{n=0}^{M} a_{l}[\underset{l}{Z}(z)]^{n}\right\} \log \frac{Z_{l}(z)+1}{Z_{l}(z)-1}-\sum_{j=0}^{M-1} b_{l}[\underset{l}{Z}(z)]^{j}, \\
& a_{l}=\frac{1}{2 \pi} \sum_{m=0}^{M}\left(\begin{array}{c}
\mathrm{i} \mu_{m}-v_{l} \\
l
\end{array}\right) \mathbf{T}_{m n}, \quad b_{l}=\frac{1}{2 \pi} \sum_{m=0}^{M}\left(\mathrm{i} \mu_{m}-v_{l}\right) \sum_{n=0}^{M} \mathbf{T}_{m n} \mathbf{C}_{n j} .
\end{aligned}
$$


Likewise, the summation in the far-field may be expressed in matrix form as

$$
\sum_{j=\operatorname{int} \frac{n+3}{2}}^{\operatorname{int}} \frac{2}{2 j-1}\left[Z_{l}(z)\right]^{n+1-2 j}=\sum_{j=1}^{J} \mathbf{F}_{n j}\left[{ }_{l}(z)\right]^{-j},
$$

where

$$
\mathbf{F}_{n j}=\left[\begin{array}{cccccccccc}
2 & 0 & \frac{2}{3} & 0 & \frac{2}{5} & 0 & \ldots & \frac{2}{j} & 0 & \ldots \\
0 & \frac{2}{3} & 0 & \frac{2}{5} & 0 & \frac{2}{7} & \ldots & 0 & \frac{2}{j+1} & \ldots \\
\frac{2}{3} & 0 & \frac{2}{5} & 0 & \frac{2}{7} & 0 & \ldots & \frac{2}{j+2} & 0 & \ldots \\
0 & \frac{2}{5} & 0 & \frac{2}{7} & 0 & \frac{2}{9} & \ldots & 0 & \frac{2}{j+3} & \ldots \\
\ldots & \ldots & \ldots & \ldots & \ldots & \ldots & \ldots & \ldots & \ldots
\end{array}\right] .
$$

This gives

$\underset{l}{\Omega(z)}=\sum_{j=1}^{J} c_{l}\left[{ }_{l}^{Z}(z)\right]^{-j}, \quad c_{l}=\frac{1}{2 \pi} \sum_{m=0}^{M}\left(\begin{array}{c}\mathrm{i} \mu_{m}-v_{l} \\ l\end{array}\right) \sum_{n=0}^{M} \mathbf{T}_{m n} \mathbf{F}_{n j} \quad(|Z|>\underset{l}{r})$.

The discharge vector is obtained from the gradient of these series. Note that the far-field series was truncated at $J=30$ with $\underset{l}{r}=1.1$ for each line in Fig. 5 .

\section{Regional-scale model}

The complex potential for the family of analytic elements associated with a field has the following form in the far-field:

$\Omega(z)=\frac{\underset{f}{Q}}{2 \pi} \log \left(z-z_{1}\right)+\sum_{l=1}^{L} \sum_{j=1}^{J} c_{l}\left(\frac{\underset{z}{z}-z_{l}}{2}\right)^{j}\left(\frac{1}{z-z_{l}}\right)^{j}$,

where $z_{l}=\left(\underset{l+1}{z}+z_{l}\right) / 2$ is the center of each line segment. This expansion is valid in a neighborhood $|z-\underset{f}{z}|>\underset{f}{r}$, where

$\underset{f}{r}=\max _{l}\left(\left|z_{f}-z_{l}\right|+\underset{l}{r}\right)$

as illustrated in Fig. 4b. Following the superblock approach [33], these terms may be gathered into a point-sink and series expansion about $z$

$\underset{f}{\Omega}(z)=\frac{\underset{f}{Q}}{2 \pi} \log \left(z-z_{f}\right)+\sum_{k=1}^{K} d_{f}[\underset{f}{Z}(z)]^{-k}, \quad \underset{f}{Z}(z)=\frac{z-z_{f}}{r}$,

where $K$ is chosen to contain numerically significant terms in the Laurent series. Note that the point $\underset{f}{z}$ with the smallest radius $\underset{f}{r}$ may be found iteratively by stepping a short distance towards the center of the element $l$ that maximizes this radius.

It is shown next how to explicitly compute the coefficients $d_{f}$ in the far-field expansion, extending the numerical methods to evaluate coefficients presented by [33]. The logarithm term for the point-sink may be written as

$\log \left(z-z_{1}\right)=\log \left(z-z_{f}\right)+\log \left(1-\frac{\underset{1}{z}-z_{f}}{r} \frac{r}{z-z_{f}}\right)$ 
and the last term is expanded as a Taylor series [22] to give

$\frac{f}{2 \pi} \log \left(z-z_{1}\right)=\frac{\underset{f}{Q}}{2 \pi} \log (z-\underset{f}{z})-\frac{\underset{f}{2 \pi}}{2 \pi} \sum_{k=1}^{\infty} \frac{1}{k}\left[\underset{f}{Z_{1}}(z)\right]^{k}[\underset{f}{Z}(z)]^{-k}$.

The term associated with the $j^{\text {th }}$ power for line elements may be written as

$$
\left(\frac{1}{z-z_{l}}\right)^{j}=\left[\frac{1}{r_{f}} \frac{1}{Z f(z)-\underset{f}{Z}\left(z_{l}\right)}\right]^{j}=\frac{1}{r_{f}^{j}}\left\{\sum_{i=1}^{\infty}\left[\underset{f}{Z}\left(z_{l}\right)\right]^{i-1}\left[\frac{1}{Z_{f}(z)}\right]^{i}\right\}^{j}
$$

using [34, p. 210]. Bell polynomials [35] provide a means to gather common terms for powers of series. Following [36, p. 133],

$$
\left(\sum_{i=1}^{I} \frac{a_{i}}{i !} x^{i}\right)^{j}=j ! \sum_{k=j}^{I j} \frac{1}{k !} \mathbf{B}_{k j}\left(a_{i}\right) x^{k} \quad(j=0,1, \ldots) .
$$

The values of the coefficients $\mathbf{B}_{k j}\left(a_{i}\right)$ may be computed recursively for specified values of $a_{i}$ following [25] using

$\mathbf{B}_{0 j}= \begin{cases}1 & (j=0) \\ 0 & (j>0)\end{cases}$

and, for $k \geq 1$

$\mathbf{B}_{k j}=\left\{\begin{array}{lc}0 & (j=0) \\ a_{k} & (j=1) \\ \frac{1}{j} \sum_{q=j-1}^{k-1}\left(\begin{array}{l}k \\ q\end{array}\right) a_{k-q} \mathbf{B}_{q(j-1)} & (1<j<k) . \\ \left(a_{1}\right)^{k} & (j=k) \\ 0 & (j>k)\end{array}\right.$

In matrix form, this gives

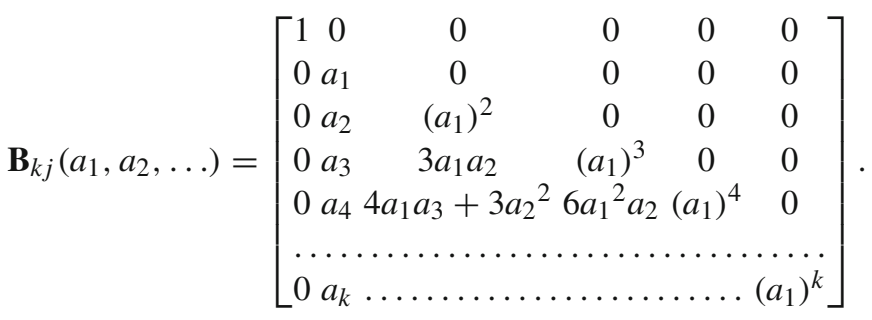

Application to the following term for line elements gives

$$
\left(\frac{1}{z-z_{l}}\right)^{j}=\frac{j !}{r_{f}^{j}} \sum_{k=j}^{I j} \frac{1}{k !} \mathbf{B}_{k j}\left\{i !\left[\underset{f}{Z_{l}\left(z_{c}\right)}\right]^{i-1}\right\}\left[\frac{1}{\underset{f}{Z}(z)}\right]^{k} \text {. }
$$

Combining the far-field expansion for the family of all line elements and the point-sink gives the coefficients in the series expansion for a field

$d_{f}=-\frac{\underset{f}{2}}{2 \pi} \frac{1}{k}\left[\underset{f}{Z}\left(\underset{1}{z_{0}}\right]^{k}+\sum_{l=1}^{L} \sum_{j=1}^{J} c_{l}\left(\frac{\underset{l+1}{z}-z_{l}}{2}\right)^{j} \frac{j !}{r_{f}^{j}} \frac{1}{k !} \mathbf{B}_{k j}\left\{i !\left[\underset{f}{Z} \underset{l}{z_{c}}\right)\right]^{i-1}\right\}$.

The number of terms used in the far-field expansion for the family of elements in (48) is $K=20$ in the next section. 


\section{Hydrologic paths from recharge to phreatophyte uptake}

This section investigates the sources of water for phreatophytes and communities of phreatophytes. Pathlines are obtained by tracing water particles from the groundwater table (phreatic surface) beneath the root zone of a plant backwards in time. A particle tracking approach is employed to identify three-dimensional points $\left(x, y, x_{3}\right)$ that lie along these pathlines. The horizontal components, $z=x+\mathrm{i} y$, are obtained using the 2nd-order Runge-Kutta method [23, Eq. 26.12] to solve

$\frac{\mathrm{d} z}{\mathrm{~d} s}=\frac{w}{|w|}$

where $s$ is the horizontal distance along the pathline. The groundwater elevation along a pathline, $x_{3}$, is obtained for unconfined flow from [23, Eq. 27.25],

$\frac{\mathrm{d}}{\mathrm{d} s}\left(\frac{x_{3}-B}{\phi-B}\right)=-\left(\frac{x_{3}-B}{\phi-B}\right) \frac{R}{|w|}$

using finite differences. Pathlines terminate in the backwards direction with respect to time when their elevation, $x_{3}$, intercept the phreatic surface where $x_{3}=\phi$.

Published values for yearly evapotranspiration by cottonwoods are summarized in Table 2. Hydraulic lift of groundwater has been estimated to account for nearly $25 \%$ of the total daily water use of the tree [21], and may move as much as 30-40\% of the water transpired during the day [37]. Near the study region, [5] calculated average groundwater uptake of $4.2 \mathrm{~mm} / \mathrm{d}$ in August when plants were maximally uptaking groundwater. For this investigation, it is assumed that the average annual groundwater root uptake is $40 \mathrm{~cm} / \mathrm{yr}$ and an ambient background recharge of $R=5 \mathrm{~cm} / \mathrm{yr}$ occurs throughout the region.

Groundwater pathlines are constructed in Fig. 6 with endpoints that lie on a circle at the elevation of the phreatic surface beneath each phreatophyte. Inside this circle, groundwater uptake is greater than the ambient rate of recharge and pathlines will go downwards when traveling backwards in time; outside the circle, the net recharge and plant uptake result in pathlines directed upwards for decreasing time. These pathlines lie on the stream surface that forms the boundary of the capture zone for a phreatophyte in a uniform flow, and is analogous to the three-dimensional capture zone for a well [40-42].

Mass balance dictates that the horizontal extent at the top of the groundwater is $8 \pi \underset{p}{2}$ for the uniform distribution in Fig. 6a, since the average groundwater uptake is 8 times larger than the ambient recharge. Thus, the horizontal extent of the capture zone over which water is captured is 8 times larger than the surface area over which groundwater uptake occurs. It is observed that the geometry of a capture zone is influenced by the functional form of groundwater uptake, where groundwater is captured from vertical elevations nearest the phreatic surface for a uniform distribution (Fig. 6a) and deepest within groundwater for a power distribution (Fig. 6c).

The source of groundwater for a community of phreatophytes is illustrated in Fig. 7 for the study region in Fig. 3. Pathlines are constructed that end at the center of a set of $10 \%$ of the cottonwoods that were randomly selected, but the same set was used to illustrate the three distributions of groundwater uptake. It is observed that pathlines for individual phreatophytes travel beneath the capture zones for upgradient plants; when tracing backwards in time in the negative $x$-direction, pathlines increase in elevation when under locations with no phreatophytes and travel deeper into groundwater when under plants with large groundwater uptake.

Table 2 Published water use (average yearly evapotranspiration over the horizontal canopy area) for cottonwood phreatophytes

\begin{tabular}{llll}
\hline Species & Evapotranspiration $(\mathrm{m} / \mathrm{yr})$ & Canopy radius $(\mathrm{m})$ & Source \\
\hline Populus deltoides & $0.95-1.34$ & & {$[7]$} \\
Populus fremontii & $0.48-0.97$ & $12-18$ & {$[38]$} \\
Populus fremontii & 1.2 & $1.5-1.7$ & {$[39]$} \\
Populus spp. & $1.0-3.3$ & & {$[11]$} \\
\hline
\end{tabular}



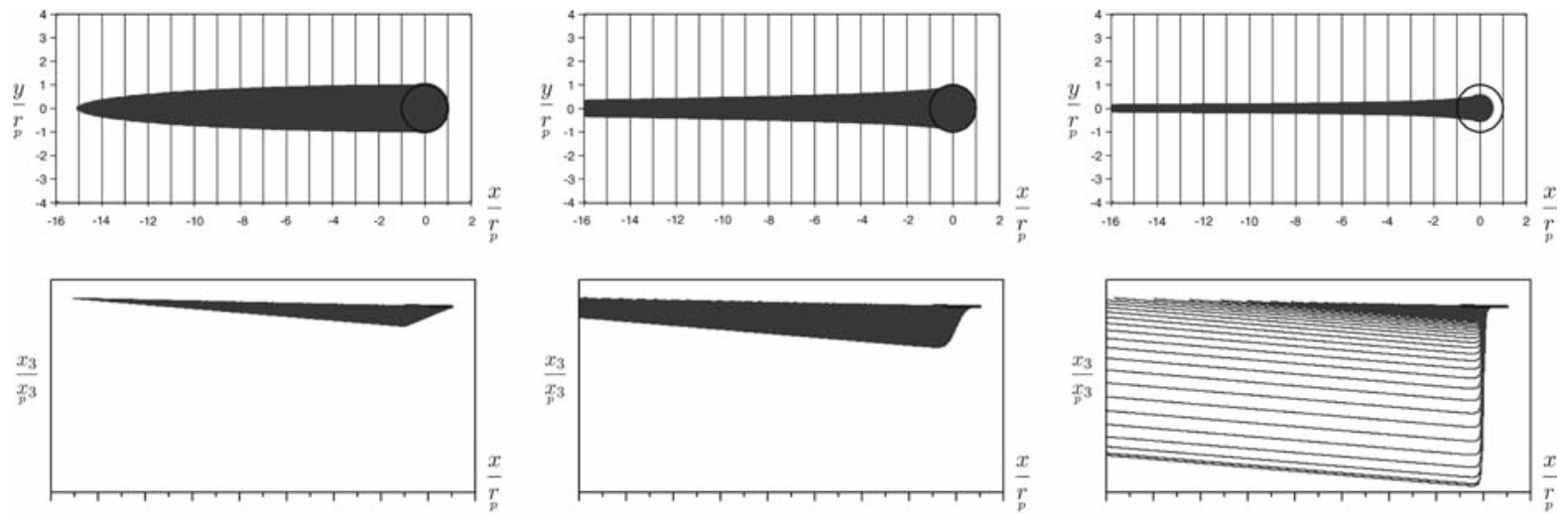

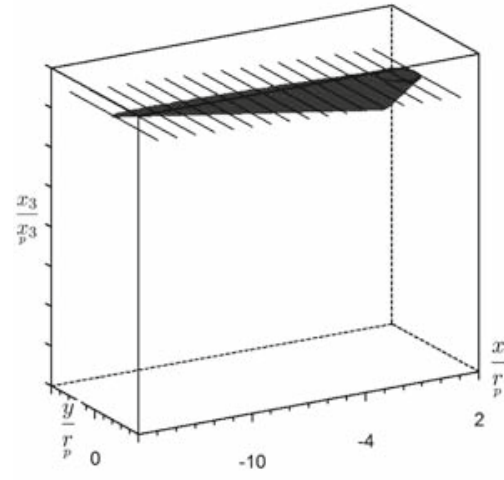

a Uniform distribution

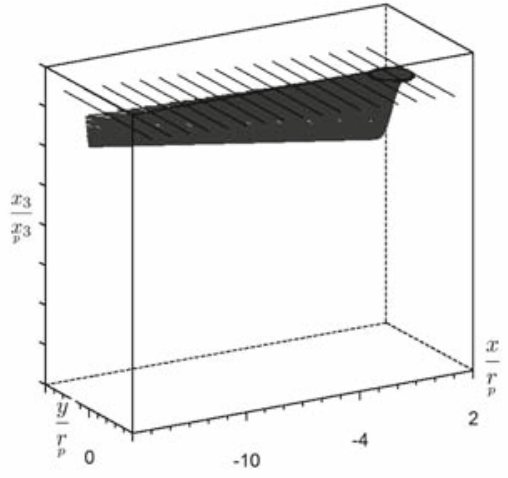

b Exponential distribution

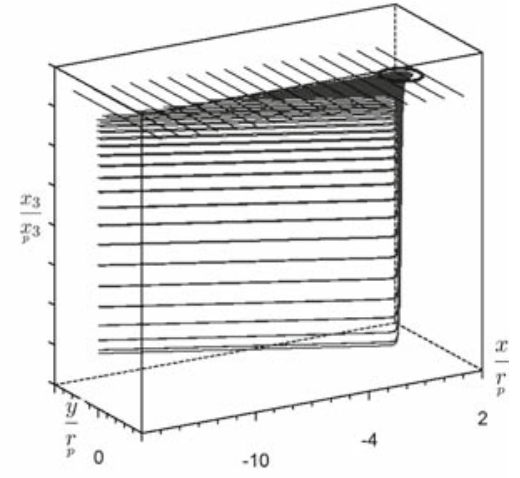

c Power distribution $(n=2)$

Fig. 6 Capture zones for a single isolated phreatophyte with specified groundwater uptake function, shown in plan (top), section (middle) and three-dimensional (bottom) views

This illustrates that capture zones may extend for significant upgradient distances and that phreatophytes have the capacity to siphon groundwater from the upper regions of an aquifer. It is observed that groundwater is removed from deeper portions of the aquifer as the groundwater-uptake function changes from a uniform distribution (Fig. 7a) to focus uptake about the taproot of a phreatophyte (Fig. $7 \mathrm{~b}$ and c). This suggests pathways for phytoremediation (uptake of nutrients or chemicals), whereby more recent groundwater that overlies older and possibly fossil groundwater is preferentially withdrawn.

This model employs the Dupuit assumption that head is uniform in the vertical direction [43]. It is known that aquifer features that do not fully penetrate an aquifer (such as phreatophytes which remove groundwater from the top of the aquifer at the phreatic surface) may generate a three-dimensional flow that requires more sophisticated mathematical development in the vicinity of the feature [44, Chap. 4]. A three-dimensional model that is similar to a phreatophyte with uniform root uptake (as in Fig. 7a) was developed by [45] who examined uniform recharge over a circular disk. Results indicate that Dupuit predictions underestimate the horizontal width of the capture zone but approach the three-dimensional results as the size of the circular disk increases. This is consistent with the findings by [41] who examined withdrawal along a horizontal line at the top of the aquifer and found that withdraw which is small compared to the discharge of groundwater flowing beneath the line (as is the case for phreatophytes in the study region) produces three-dimensional streamlines with similar topology to Fig. 6a. Phreatophytes with withdrawal focused about a taproot (Fig. 7c), approach the limiting case of a three-dimensional point-sink located at the top of the aquifer. This three-dimensional flow was compared to the Dupuit approximation by [46] who found that differences in head between the two models become small as the discharge of withdrawn water decreases. 

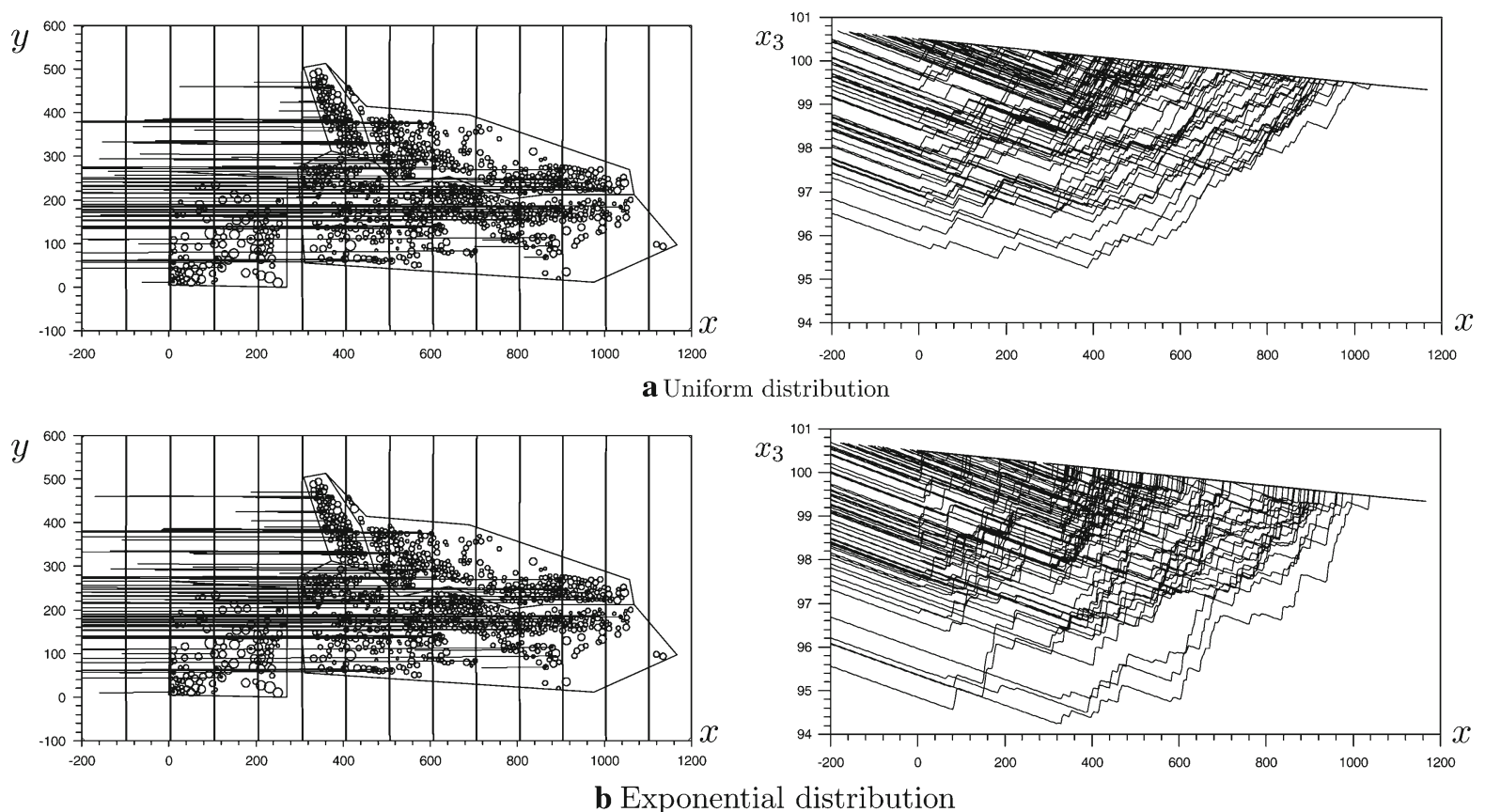

b Exponential distribution

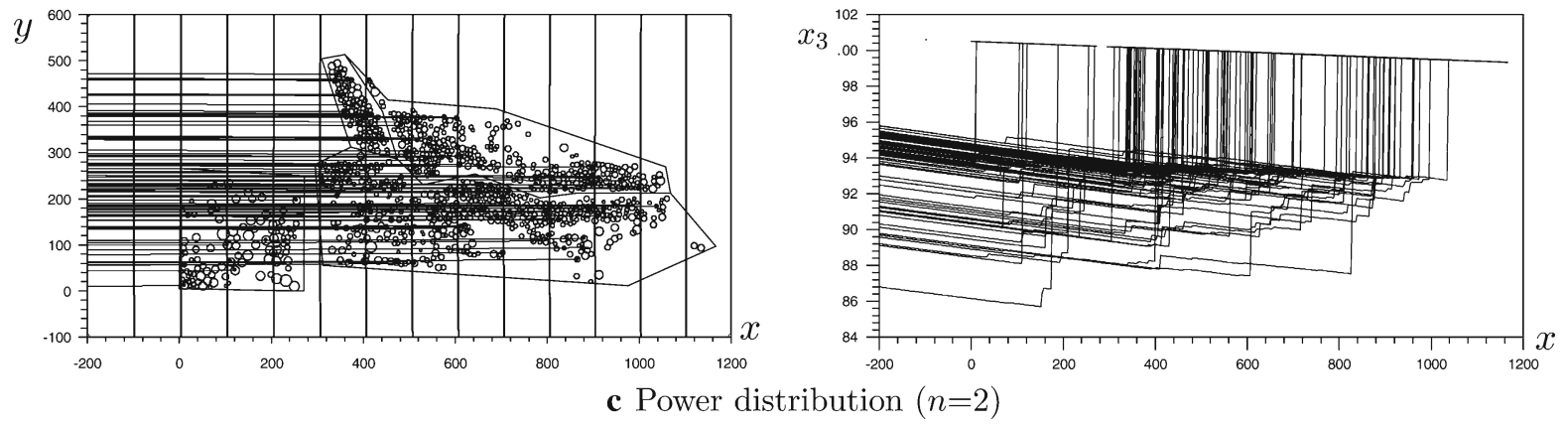

Fig. 7 The source of groundwater for a community of phreatophyte (shown in plan and section views): pathlines are traced backwards in time from the center of $10 \%$ of randomly selected plants using the same random set for each distribution of groundwater uptake

\section{Conclusions}

Mathematical expressions were developed for the specific discharge of groundwater uptake by a phreatophyte, $-R$, based upon uniform, exponential, and power distributions, (1). Their coefficients, (4), are expressed as a function of the discharge of groundwater uptake by a plant, $\underset{p}{Q}$, and the horizontal radius of the plant canopy, $\underset{p}{r}$. Wirtinger calculus was employed to develop expressions for the groundwater discharge per width, $w$ in (14), and potential, $\Phi$ in (16). The groundwater-uptake functions are illustrated in Fig. 1, and the potential and discharge are shown in Fig. 2. These distributions reflect the ability of phreatophytes to extract groundwater which is dependent on the plant's age, where adult trees with roots distributed continuously throughout the soil profile have the most active water absorption in deeper soil layers [12].

Field scale models were developed that summed the mathematical expressions for all phreatophytes within a field, (18) and (19). Groundwater flow is illustrated for phreatophytes within a field (Fig. 4a) in a study region located near the Larned test site of [5] in Fig. 3. The concept of an area-sink was extended from existing implementations for polynomial [23, Sect. 37] and multi-quadrics [31] distributions using higher-order Chebyshev strength distributions [32]. The complex potential, (25), and discharge vector, (27), for Cauchy integrals were used to satisfy conditions 
of continuity of head, (31), and continuity of flow, (34), at the boundary of the field. The jumps in potential and normal components of flow, as well as the comprehensive flow generated by a field, are illustrated in Fig. 5 .

A regional scale model was obtained by first developing Taylor, (42), and Laurent, (45), series for Cauchy integrals with known coefficients. These series were rearranged using Bell polynomials, (53), to achieve a single Laurent series plus a point-sink, (48), with coefficients in Eq. (56). This extends the numerical method used to compute coefficients in the superblock approach [33]. This formulation is valid in the far-field of the family of analytic elements associated with a field (Fig. 4b), and provides a computational efficient method to incorporate fields of phreatophytes within a single model.

Hydrologic pathways from recharge to groundwater uptake were investigated by tracing groundwater particles backwards in time from groundwater beneath the root zone. Capture zones were constructed for an isolated phreatophyte in a uniform flow in Fig. 6. This illustrates the horizontal regions over which a plant extracts groundwater and shows the impact of the functional form of groundwater uptake, where groundwater is captured nearest the groundwater surface for a uniform distribution and deepest in the groundwater column for a power distribution. Investigation of pathways for communities of phreatophytes in Fig. 7 indicates that plant communities siphon source water from the uppermost groundwater regions. Groundwater pathlines extend to greater horizontal depths and lateral extent as they pass beneath the capture zones of upgradient phreatophytes.

Considerable spatial variation in phreatophyte groundwater uptake has been observed [5], and may vary with depth to groundwater and intermittency of surface water [13,20,38]. Human activities (e.g. pumping), climatic change (e.g. drought), and species composition may impact a phreatophytic community's ability to tap groundwater. This mathematical and computational model supports a wide-range of hypothesis testing and exploration with field instrumentation and interpretation of their data to understand the function of phreatophytes in water and nutrient uptake across plant to regional scales.

Acknowledgements The authors gratefully acknowledge financial support provided by the Provost Office's Targeted Excellence Program at Kansas State University, the National Science Foundation (grant EPS0553722), and the United States Department of Agriculture/Agriculture Research Service (Cooperative Agreement 58-6209-3-018). We thank John L. Nieber, Otto D. L. Strack, A. W. Warrick and one anonymous reviewer for their very thorough and insightful review comments that clarified and strengthened contributions.

Open Access This article is distributed under the terms of the Creative Commons Attribution Noncommercial License which permits any noncommercial use, distribution, and reproduction in any medium, provided the original author(s) and source are credited.

\section{References}

1. Ripl W (2003) Water: the bloodstream of the biosphere. Philos Trans R Soc Lond B 358:1921-1934

2. Foster SSD, Chilton PJ (2003) Groundwater: The processes and global significance of aquifer degradation. Philos Trans R Soc Lond B 358:1957-1972

3. UNESCO (2003) Water for people, water for life - un world water development report. UNSECO Publishing, Berghann Books, UK (http://www.unesco.org/water/wwap), March 2003

4. Livingston ML, Garrido A (2004) Entering the policy debate: an economic evaluation of groundwater policy in flux. Water Resour Res 40:W12S02

5. Butler JJ Jr, Kluitenberg GJ, Whittemore DO, Loheide II SP, Jin W, Billinger MA, Zhan X (2007) A field investigation of phreatophyte-induced fluctuations in the water table. Water Resour Res 43:W02404

6. Dawson TE (1993) Hydraulic lift and water use by plants: implications for water balance, performance and plant-plant interactions. Oecologia 95:575-574

7. Cleverly JR, Dahm CN, Thibault JR, McDonnell DE, Allred Coonrod JE (2006) Riparian ecohydrology: regulation of water flux from the ground to the atmosphere in the Middle Rio Grande, New Mexico. Hydrol Process 20:3207-3225

8. Canadell J, Jackson RB, Ehleringer JR, Mooney HA, Sala OE, Schulze ED (1996) Maximum rooting depth of vegetation types at the global scale. Oecologia 108:583-595

9. Lee J-E, Oliveira RS, Dawson TE, Fung I (2005) Root functioning modifies seasonal climate. Proc Nat Acad Sci USA 102(49):17576-17581

10. Glenn EP, Nagler PL (2005) Comparative ecophysiology of tamarix ramosissima and native trees in western U.S. riparian zones. J Arid Environ. 61:419-446

11. Shafroth PB, Cleverly JR, Dudley TL, Taylor JP, VanRiper III C, Weeks EP, Stuart JN (2005) Control of Tamarix in Western United States: Implications for water salvage, wildlife use, and riparian restoration. Environ Manag 35(3):231-246 
12. Dawson TE, Ehleringer JR (1991) Streamside trees that do not use stream water. Nature 350(28):335-337

13. Baird KJ, Stromberg JC, Maddock T (2005) Linking riparian dynamics and groundwater: an ecohydrologic approach to modeling groundwater and riparian vegetation. Environ Manag 36(4):551-564

14. Jobbágy EG, Jackson RB (2007) Groundwater and soil chemical changes under phreatophytic tree plantations. J Geophy Res 112:G02013

15. Vörösmarty CJ, Green P, Salisbury J, Lammers RB (2000) Vulnerability from climate change and population growth. Science 289:284-288

16. Baron JS, LeRoy Poff N, Angermeier PL, Dahm CN, Gleik PH, Hairston Jr NG, Jackson RB, Johnston CA, Richter BD, Steinman AD (2002) Meeting ecological and societal needs for freshwater. Ecol Appl 12(5):1247-1260

17. Cash DW, Clark WC, Alcock F, Dickson NM, Eckley N, Guston DH, Jäger J, Mitchell RB (2003) Science and technology for sustainable development special feature: Knowledge systems for sustainable development. Proc Nat Acad Sci USA 100(14):80868091

18. Newman BD, Wilcox BP, Archer SR, Breshears DD, Dahm CN, Duffy CJ, McDowell NG, Phillips FM, Scanlon BR, Vivoni ER (2006) Ecohydrology of water-limited environments: a scientific vision. Water Resour Res 42(6):W06302

19. Oki T, Kanae S (2006) Global hydrological cycles and world water resources. Science 313:1068-1072

20. Naumburg E, Mata-Gonzalez R, Hunter RG, Mclendon T, Martin DW (2005) Phreatophytic vegetation and groundwater fluctuations: a review of current research and application of ecosystem response modeling with an emphasis on Great Basin vegetation. Environ Manag 35(6):726-740

21. Caldwell MM, Dawson TE, Richards JH (1998) Hydraulic lift: consequences of water efflux from the roots of plants. Oecologia 113:151-161

22. Abramowitz M, Stegun IA (1972) Handbook of mathematical functions. Dover Publications, New York

23. Strack ODL (1989) Groundwater mechanics. Prentice Hall, Englewood Cliffs NJ

24. Strack ODL (2003) Theory and applications of the analytic element method. Rev Geophys 41(2):1-19

25. Steward DR, Le Grand P, Janković I, Strack ODL (2008) Analytic formulation of Cauchy integrals for boundaries with curvilinear geometry. Proc R So Lond Ser A 464:223-248

26. Wirtinger W (1927) Zur formalen theorie der funktionen von mehrenen komplexen veranderlichen. Mathematischen Annalen 97:357-375

27. Remmert R (1991) Theory of complex functions. Springer-Verlag, New York. Translated by Robert B. Burckel

28. Strack ODL (2006) Discharge potential for a pond with elliptical boundary. In Proceedings of the 5th International Conference on the analytic element method, p 164-171, Kansas State University, Manhattan, KS, May 14-17 2006

29. Gröbner W, Hofreiter N (1975) integraltafel. Springer-Verlag, Vienna

30. de Lange WJ (2006) Development of an analytic element ground water model of the Netherlands. Ground Water, 44(1):111-115

31. Strack ODL, Janković I, Barnes RJ (1999) The superblock approach for the analytic element method. J Hydrol 226(3-4):179-187

32. Janković I, Barnes RJ (1999) High-order line elements in modeling two-dimensional groundwater flow. J Hydrol 226(3-4):211-223

33. Strack ODL (1999) Principles of the analytic element method. J Hydrol 226:128-138

34. Hille E (1982) Analytic function theory: Volume 1. Chelsea Publishing Company, New York

35. Bell ET (1934) Exponential polynomials. Ann Math 35(2):258-277

36. Comtet L (1974) Advanced combinatorics; The art of finite and infinite expansions. D. Reidel Pub. Co., Dordrecht, Boston

37. Ehrenfeld JG, Ravid B, Elgersma K (2005) Feedback in the plant-soil system. Environ Resour 30:75-115

38. Gazal RM, Scott RL, Goodrich DC, Williams DG (2006) Controls on transpiration in a semiarid riparian cottonwood forest. Agric For Meteorol 137:56-67

39. Nagler P, Jetton A, Fleming J, Didan K, Glenn E, Erker J, Morino K, Milliken J, Gloss S (2007) Evaporation in a cottonwood (Populus fremontii) restoration plantation estimated by sap flow and remote sensing methods. Agricu For Meteorol 144:95-110

40. Steward DR (1998) Stream surfaces in two-dimensional and three-dimensional divergence-free flows. Water Resour Res 34(5): $1345-1350$

41. Steward DR (1999) Three-dimensional analysis of the capture of contaminated leachate by fully penetrating, partially penetrating, and horizontal wells. Water Resour Res 35(2):461-468

42. Steward DR, Jin W (2003) Drawdown and capture zone topology for non-vertical wells. Water Resour Res 39(8):9-111

43. Strack ODL (1984) Three-dimensional streamlines in Dupuit-Forchheimer models. Water Resour Res 20(7):812-822

44. Haitjema HM (1985) Modeling three-dimensional flow in confined aquifers by superposition of both two- and three-dimensional analytic functions. Water Resour Res 21(10):1557-1566

45. Haitjema HM (1987) Comparing a three-dimensional and a Dupuit-Forchheimer solution for a circular recharge area in a confined aquifer. J Hydrol 91:83-101

46. Steward DR, Jin W (2006) Uniform head in horizontal and vertical wells. Ground Water 44(1):86-90 